\title{
Análise da fisionomia da cobertura vegetal em ambientes semiáridos: o caso do município de Jaguaretama, estado do Ceará
} Analysis of the physiognomy vegetation cover in environments semiarid: the case of the
municipality Jaguaretama, State of Ceará

Silva ${ }^{1}$, F. C.; $\mathrm{Cruz}^{2}$, M. L. B.

carliane.silva@aluno.uece.br

\section{Resumo}

Considerando a crescente discussão acerca dos problemas ambientais no semiárido cearense, o presente trabalho versa sobre as atuais condições fisionômicas da vegetação no município de Jaguaretama/Ceará, cujo processo de degradação ambiental tem contribuído para descaracterização da paisagem vegetacional da área. Nesta perspectiva, o texto discute os aspectos relacionados com alguns conjuntos fisionômicos da vegetação da Caatinga por meio da identificação e reconhecimento das densidades e tipos vegetacional no município de Jaguaretama. Assim, conforme os valores alcançados com a aplicação do Índice de Vegetação Ajustado ao Solo (SAVI) foram identificadas variadas classes de vegetação de acordo com a atividade fotossintética, associada a presença de solo exposto, como consequência da supressão da cobertura vegetal e o agravamento dos efeitos degradacionais.
Palavras-chave: Cobertura Vegetal. Semiárido. Índice de vegetação.

Abstract

Considering the growing discussion about the environmental problems in the semiarid cearense, this paper deals with the current physiognomy conditions of vegetation in the municipality of Jaguaretama/Ceará, whose environmental degradation has contributed to mischaracterization of the vegetation of the area landscape. The text discusses aspects related to some sets physiognomic vegetation Caatinga through the identification and recognition of densities and vegetation types in the municipality of Jaguaretama. Values achieved with Soil adjusted vegetation index (SAVI) varied vegetation classes identified in accordance with the photosynthetic activity, associated the presence of exposed soil, consequence of abolishing the vegetation cover and the worsening effects degradation.

Keywords: Vegetal Cover. Semiarid. Vegetation Index.

\section{INTRODUÇÃO}

A aproximação do conhecimento acerca das diversidades e heterogeneidades da vegetação em ambientes semiáridos tem como base o entendimento e a compreensão das peculiares de sua composição e distribuição. Tal fato deve estar associado à dinâmica dos demais componentes naturais que incidem e contribuem de forma significativa para a apreensão do quadro degradacional

${ }^{2}$ Maria Lúcia Brito da Cruz, Laboratório de Geoprocessamento e Estudos Aplicados (LABGEO), Universidade Estadual do Ceará, 
dos ambientes secos brasileiros, cujos padrões de vegetação expressam-se pela preponderância de fisionomias das caatingas.

Para diversos autores, uma abordagem da fisionomia de um determinado conjunto vegetacional requer a compreensão de sua aparência geral externa como o porte, a fenologia e a densidade dos seus componentes, tornando-se possível inferir questões como conservação e degradação, a partir das características e atributos próprios dos padrões predominantes (TRICART, 1977; FERNANDES e BEZERRA, 1990; SOUZA 2000).

Fernandes (2003) ao pesquisar o conjunto vegetacional das caatingas na região semiárida do Nordeste brasileiro, destacou a predominância de dois tipos fisionômicos de vegetação, a saber: um arbóreo (alto porte) e outro arbustivo (baixo porte), sempre recoberto por um estrato herbáceo efêmero.

Como reflexo da interação dos componentes ambientais nas paisagens naturais, a vegetação exerce função primordial na retenção da energia da precipitação, devido ao processo de infiltração da água no solo capaz de amenizar os impactos gerados pelo escoamento artificial e ações erosivas dos solos, implicando assim em graves consequências para o equilíbrio e dinâmica ambiental (TRICART, 1977).

A região do semiárido brasileiro possui cerca de $800.000 \mathrm{~km}^{2}$ e seu território encontrase preponderantemente recoberto por vegetação xerófila, de aspecto fisionômico e florístico variado. Caracterizada pela completa caducifolia, na maior parte dos seus componentes; a vegetação caatinga demonstra uma particularidade de adaptação à deficiência hídrica ocasionada pela baixa pluviosidade e elevadas taxas de evapotranspiração potencial, associado à formação de solos pouco profundos nos terrenos do embasamento cristalino (RODAL et al., 2013).

Nesse contexto, insere-se o estado do Ceará, cujo bioma caatinga apresenta características geobotânicas que não diferem, de forma geral, do contexto ambiental nordestino. Aliando-se a esse pensamento, Souza (2006) e Ceará (2010) ressaltam que o uso e a ocupação da terra vêm contribuindo para profundas transformações no cenário das caatingas, exibindo, dessa forma, marcas de degradação ambiental nas paisagens do semiárido cearense.

Diante do exposto, a presente pesquisa teve como objetivo identificar, a partir da atividade fotossintética, as fisionomias da vegetação do município de Jaguaretama, estado do Ceará, área considerada em processo de degradação ambiental.

\subsection{Localização e caracterização geoambiental da área de estudo}


Localizado na porção centro-leste do estado do Ceará, o município de Jaguaretama está inserido na bacia hidrográfica do Banabuiú. O referido município é delimitado por uma Latitude de 5³6'46" Sul e Longitude de 3846'01" Oeste. A área estudada possui extensão territorial de $1.759,72 \mathrm{~km}^{2}$, e sua sede municipal situa-se a $213 \mathrm{~km}$ de Fortaleza, capital do estado (IPECE, 2014). Tendo como principal via de acesso às rodovias estaduais CE 368 e CE 371.

Inserido nos domínios da depressão sertaneja, o município de Jaguaretama está disposto sobre terreno do embasamento cristalino, onde a geologia, compreendida dentro de um contexto litológico regional, é representada por rochas cristalinas antigas do Pré-Cambriano Indiviso (rochas do tipo quartzitos, gnáissicas e migmatíticas). É importante salientar, ainda, que esse relevo se classifica como plano à suave ondulado (CPRM, 1974).

Sob a influência do clima semiárido, as condições pluviométricas da área em estudo se apresentam de forma irregular no tempo e no espaço; com média pluviométrica de $700 \mathrm{~mm}$ anual, as chuvas se concentram nos meses de janeiro a abril, elevando as temperaturas e os totais de evapotranspiração ao longo de todo o ano, favorecendo a um baixo potencial no armazenamento hídrico (SOUZA et al. 2002; FUNCEME, 2009).

Como reflexo da interação dos componentes supracitados, a vegetação do município de Jaguaretama é constituída pela caatinga hiperxerófila, caracterizada pela caducidade das suas folhas com formações arbóreo-arbustiva, predominando cactáceas, espécies lenhosas e espinhentas que se sobressaem em meio à presença de solos pouco profundos, cujas propriedades morfológicas, físicas e químicas desencadeiam processos erosivos (FUNCEME, 2009).

\section{METODOLOGIA}

Foi fundamental para o desenvolvimento desta pesquisa o processo de construção teórico-metodológica a partir do levantamento das referências bibliográficas, disponíveis em forma de artigos científicos, monografias, dissertações, teses e livros, permitindo verificar a existência de produção científica para a área em estudo e a aproximação com as bases teórico-conceituais apresentadas neste trabalho.

No tocante a etapa de aquisição de dados geocartográficos, foi necessário o uso de bases cartográficas em arquivos vetoriais, sendo eles: os limites municipais em escala de 1.250.00, disponibilizados pelo Instituto Brasileiro de Geografia e Estatística (IBGE); rede de drenagem superficial e sede municipal fornecidas pela Fundação Cearense de Meteorologia (FUNCEME); das vias pavimentadas pelo Instituto de Pesquisa e Estratégia Econômica do Ceará (IPECE). Os arquivos citados foram utilizados para elaboração do mapa de localização, com escala de mapeamento de 1.80.000, gerado via software Quantum GIS 2.14.3-Essen. 
Para analisar e interpretar as características e os tipos de vegetação no município em epígrafe, foi necessário a obtenção das imagens orbitais do sensor Operational Land Imager (OLI), acoplado ao satélite Landsat 8, com resolução radiométrica de 16 bits e espacial de 30 metros para a região do visível, infravermelho próximo e médio, obtidas através do site United States Geological Survey (USGS), nas órbitas 216 e 217, ponto 64, datadas em 15/09/2014 e 22/09/2014, respectivamente. A escolha das imagens se justifica pela qualidade das imagens e baixa cobertura de nuvens nesse período do ano, tratadas no software Spring 5.3.

Desta forma, para alcançar os valores possíveis de representarem os diferentes alvos na superfície terrestre, foi realizada a transformação dos valores de Números Digitais (NDs) das imagens em valores físicos de Reflectância Bidirecional Aparente (FRB aparente), a fim de obter melhor acurácia dos dados referentes às propriedades espectrais de objetos para prosseguir com as operações aritméticas (PONZONI; SHIMABUKURO, 2009).

Assim, para a determinação dos valores de FRB aparente, foi aplicada a equação adaptada para o sensor Operational Land Imager (OLI):

$$
\rho \lambda=\frac{\rho \lambda^{\prime}}{\cos (\theta s z)}=\frac{\rho \lambda^{\prime}}{\sin (\theta s \epsilon)}
$$

Onde: $\rho \lambda$ é a reflectância no topo da atmosfera; $\theta s \epsilon$ corresponde ao local de elevação do ângulo solar; $\theta s z$ é o local do ângulo solar zenital.

Os índices de vegetação são, conforme Ponzoni e Shimabukuro (2009), capazes de fornecer e explorar as propriedades espectrais da vegetação, sendo fundamentados, especialmente, no comportamento antagônico da reflectância da vegetação na região do visível e infravermelho próximo.

Entre os mais variados índices de vegetação apresentados pela literatura, o Índice de Vegetação Ajustado ao Solo (SAVI), adaptado do Índice de Vegetação da Diferença Normalizada (NDVI) por Huete, em 1988, possui a propriedade de inibir o efeito do brilho do solo em áreas que apresentam vegetação esparsa. Nesse caso, a constante de ajuste ao solo, representada pelo fator L, demonstra as características pela reflectância do solo (calor e brilho) dependendo da densidade da vegetação analisada. (PONZONI e SHIMABUKURO, 2009), conforme a Equação:

$$
S A V I=\frac{(1+L)(N I R+R E D)}{N I R+R E D+L}
$$

Sendo: L o fator de ajuste ao solo, com valor de 0,25. 
Considerando a importância do sensoriamento remoto para a análise da vegetação em áreas degradadas do semiárido nordestino, Rocha (2016), ao comparar o desempenho entre os índices de vegetação NDVI e SAVI, conclui que o SAVI apresentou melhor precisão no reconhecimento da atividade fotossintética da biomassa na região do Seridó ocidental paraibano, tornando-se, dessa forma, o mais indicado para análises da vegetação em áreas semiáridas.

O fatiamento das classes atendeu aos valores encontrados na imagem índice, quais sejam: o intervalo entre -1 e 0 , a classe associada foi de corpos hídricos; de 0 a 0.19 , atribuiu a presença de solo exposto; de 0.19 a 0.3 , classe de vegetação com baixa atividade fotossintética; de 0.3 a 0.5 , vegetação com média atividade fotossintética; e por fim, os valores de 0.5 a 0.8 para a classe de vegetações com alta atividade fotossintética.

Para auxiliar na interpretação e na análise do comportamento espectral dos alvos vegetação e solo exposto, foi gerado o mapa final do índice de vegetação SAVI com as classes correspondentes aos valores encontrados.

\section{RESULTADOS E DISCUSSÃO}

Com $1.118,049 \mathrm{~km}^{2}$, o que representa $64,5 \%$, a vegetação com baixo processo fotossintético apresentou maior predominância em relação aos demais tipos de classes (Tabela 01). Os valores de reflectâncias apresentados na imagem índice de vegetação SAVI, entre 0.19 a 0.3, estão associados a uma fisionomia de vegetação de estrato herbáceo e arbustiva aberta. Nesse sentido, considerando a caducifólia das plantas em períodos mais secos e de baixas taxas pluviométricas ao longo do ano, a atividade da fitomassa da classe de baixa atividade fotossintética apresentou-se bastante reduzida no ano de 2014.

Tabela 01. Área em absoluta $\left(\mathrm{km}^{2}\right)$ e relativa $(\%)$ para cada classe de cobertura vegetal mapeada. Fonte: Autores (2016).

\begin{tabular}{c|c|c}
\hline Classes & Área $\left(\mathbf{K m}^{\mathbf{2}}\right)$ & $\mathbf{\%}$ \\
\hline Água & 17,0415 & $0,969 \%$ \\
\hline $\begin{array}{c}\text { Solo Exposto } \\
\text { fogetação baixa atividade } \\
\text { fotossintética }\end{array}$ & 590,1354 & $33,568 \%$ \\
\hline $\begin{array}{c}\text { Vegetação média atividade } \\
\text { fotossintética }\end{array}$ & $1.118,0493$ & $63,597 \%$ \\
\hline $\begin{array}{c}\text { Vegetação alta atividade } \\
\text { fotossintética }\end{array}$ & 1,2258 & $1,795 \%$ \\
\hline Área Total & 1.758 & $0,070 \%$ \\
\hline
\end{tabular}


Ainda considerando a Tabela 01, quanto ao solo exposto, observa-se que para essa classe a área em percentual corresponde a 33,5\% de extensão, sendo a segunda classe mais dominante em relação à área total do município, distribuindo-se por 590,1354 km². Destaca-se que a classe de solo exposto está disposta em relevo plano a suave ondulado associado à maior predominância da ordem dos Neossolos, Planossolos e Luvissolos.

Enfatiza-se que a associação das formações vegetais no município de Jaguaretama encontra-se em meio às condições pedológicas diversificadas, emergindo em áreas cujas condições de solos rasos e pedregosos apresentam limitações físicas e muitas vezes decorrentes de atividades agropastoris inadequadas. Favorecendo, assim, o processo de degradação de determinados componentes ambientais, a exemplo dos solos.

Nesse contexto, a partir das constantes práticas agrícolas inadequadas e desordenadas, cujo processo de desmatamento e exploração de novos ambientes é ocasionado pela atividade pecuária extensiva e ao aproveitamento vegetal da lenha são, dentre as principais ações responsáveis para o agravamento do processo de degradação ambiental, as que mais se destacam no município de Jaguaretama (CEARÁ, 2010).

Outro fator que contribui para a perda e degradação dos solos são os processos erosivos, que decorrentes da ação dos agentes erosivos como a água, o vento e a interferência humana - a partir das atividades inapropriadas, alteram os horizontes superficiais dos solos.

Deve-se ressaltar que os valores inferidos para cada classe a partir da álgebra do índice de vegetação SAVI foi realizado com imagens de um ano considerado seco, com média pluviométrica de $522 \mathrm{~mm}$ distribuídos ao longo do ano de 2014 (FUNCEME, 2016). O referido ano apresentou precipitações mais concentradas nos primeiros cinco meses e um déficit nos últimos sete meses, influenciando no ressecamento dos solos e na descaracterização da paisagem, a partir da retirada da cobertura vegetal sadia.

Assim, deve-se frisar que a predominância das classes de vegetação com baixa atividade de fotossíntese e solo exposto nesse período do ano está diretamente relacionada às condições hídricas e climáticas do período, tendo em vista a caducifolia das plantas e a redução da vegetação sadia e a diminuição da densidade vegetacional.

$\mathrm{Na}$ análise da classe da vegetação com média e alta atividade fotossintética, recobrindo $1,795 \%$ e 0,007\% da área total respectivamente (Figura 01), é possível verificar que a maior concentração de biomassa ativa se encontra, principalmente, ao longo das bordas dos corpos 
hídricos, como os rios e olhos d'água de diferentes níveis, favorecendo maior atividade e densidade vegetacional.

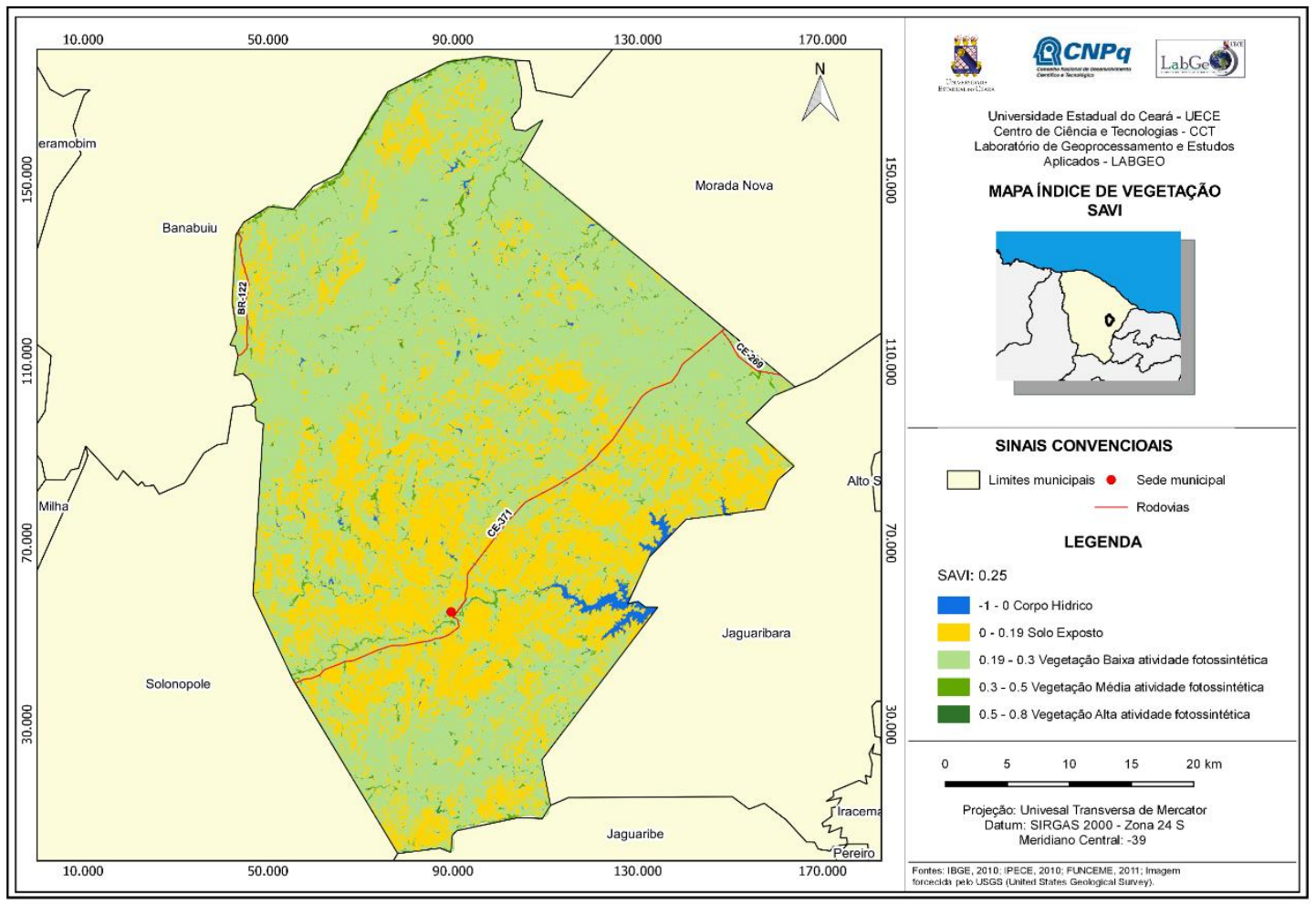

Figura 01: Mapa índice de vegetação SAVI. Fonte: Autores (2016).

No entanto, a presença de cobertura vegetal com médio potencial de fotossíntese não ocorre apenas nas margens dos corpos hídricos, como mata ciliar, mas nas fisionomias do tipo vegetacional de estrato arbustivo aberto ou caatinga baixa; sendo essa caracterizada, de acordo com Fernandes (1990), por arbustos distanciados e dispersos em meio a solos desnudos ou com recobrimento de vegetação herbácea em períodos de maior umidade, de modo que a estrutura dos indivíduos não ultrapasse a altura de 2 metros.

No município de Jaguaretama, a presença do padrão de caatinga arbustiva aberta se expressa de forma bastante significativa em boa parte do município; entretanto, esse padrão não se encontra tão visível na Figura 01 devido à ausência de folhas e, consequentemente, do processo de fotossíntese ativa em decorrência do baixo regime pluviométrico nos meses que antecederam a aquisição da imagem.

Em relação à fisionomia de caatinga densa, Fernandes (1990) aponta para a presença de arbustos entre 2 a 3 metros de altura, com considerável ramificação entre os arbustos e arvoretas do tipo xerófita, caducifólia e espinhenta. $\mathrm{Na}$ área em estudo, o padrão, ora mencionado, compreende uma zona de 0,070\% de vegetação com alta atividade de fotossíntese, o que significa uma 
inexpressível presença de caatinga arbustiva-arbóreo densa e, como consequência, poucas áreas conservadas.

Nessas condições, o processo de degradação ambiental, analisado de forma pontual no munícipio de Jaguaretama, se expressa pelos nítidos efeitos da supressão da cobertura vegetal e dos processos de degradação dos solos provocados pela a atuação dos agentes erosivos e de problemas associados ao uso da terra, incidindo desta forma em áreas com acentuada exposição da superfície.

\section{CONSIDERAÇÕES FINAIS}

O estudo realizado, a partir do aporte teórico e metodológico exposto, resultou na identificação das classes de cobertura vegetal por meio da variação da energia refletida no momento do imageamento no município de Jaguaretama. Nesse sentido, a partir do fatiamento da imagem através do SAVI, foram identificadas classes de totalidades da cobertura vegetal, subdivididas em vegetação com baixa, média e alta atividade fotossintética, presença de solo exposto e valores negativos associados aos corpos hídricos do município.

A partir da reflectância emitida pelo comportamento espectral da vegetação na região do infravermelho próximo foi possível verificar, de modo abrangente, a densidade vegetacional associada à presença de vegetação em seu estado sadio, ou seja, com acentuada assiduidade das folhas nas plantas. No entanto, observa-se que o predomínio da classe de vegetação com baixa atividade fotossintética, que corresponde a quase toda a área territorial do município, decorre das condições pluviométricas para os meses que antecedem a aquisição da imagem.

Portanto, os resultados aqui apresentados devem ser aliados a outros elementos da dinâmica da paisagem, componentes ambientais e sociais, de forma integrada, visando uma análise do processo de degradação ambiental de forma mais acurada. Desse modo, é possível uma compreensão holística dos agentes degradacionais, a fim de não inferir, a partir de uma abordagem individual dos elementos naturais, um problema de maior dimensão, que é o processo de degradação ambiental.

\section{REFERÊNCIAS}

CEARÁ. Programa de ação estadual de combate à desertificação e mitigação dos efeitos da seca. Fortaleza: Ministério do Meio Ambiente e Secretaria dos recursos Hídricos, 2010.

CPRM - Companhia de Pesquisa e Recursos Minerais. Departamento Nacional de Produção Mineral DNPM. Projeto rio Jaguaribe: relatório de fotointerpretação. Ministério das Minas e Energia/Dep. Nacional da produção mineral/ Convênio DNPM/CPRM. Recife, 1974. Disponível em: < http://www.cprm.gov.br/publique/Geologia/Geologia-Basica/Projeto-Jaguaribe-SW-419.html>. Acesso em: 26 abr. 2016. 
FERNANDES, A.. Conexões florísticas do Brasil. Fortaleza: Banco do Nordeste, 2003.

FERNANDES, A.; BEZERRA, P.. Estudo fitogeográfico do Brasil. Fortaleza: Stylus Comunicação, 1990.

FUNCEME - Fundação Cearense de Meteorologia e Recursos Hídricos. Posto pluviométrico de Jaguaretama de 1985 a 2016. Disponível em: <http://www.funceme.br/index.php/areas/23onitoramento/meteorol\%C3\%B3gico/572-postos-pluviom\%C3\%A9tricos>. Acesso: 13 abr. 2016.

FUNCEME - Fundação Cearense de Meteorologia e Recursos Hídricos. Degradação e susceptibilidade aos processos de desertificação na microrregião do Médio Jaguaribe e parte das microrregiões do Baixo Jaguaribe e Serra do Pereiro, Fortaleza, 2009.

IPECE - Instituto de Pesquisa e Estratégia Econômicas do Ceará. Perfil Básico Municipal 2014 -

Jaguaretama. Disponível em: <http://www.ipece.ce.gov.br/publicacoes/perfil_basico/pbm-

2014/Jaguaretama.pdf >. Acesso em: 11 abr. 2016.

PONZONI, F. J.; SHIMABUKURO, Y. E.. Sensoriamento remoto no estudo da vegetação. Rio de Janeiro: Parênteses, 2009.

ROCHA, N. M.. Avaliação dos índices NDVI e SAVI para Caatinga do Seridó Ocidental do Estado da Paraíba. 2016. 59f. Trabalho de Conclusão de Curso (Graduação em Geografia) - Centro de Ciências e Tecnologia, Universidade Estadual do Ceará, Fortaleza, 2016.

RODAL, M. J. N.; SAMPAIO, E. V. S. B.; FIGUEIREDO, M. A. (Orgs). Manual sobre métodos de estudo florístico e fitossociológico: ecossistema caatinga. Brasília: SB, 2013.

SOUZA, M. J. N.. Panorama da degradação ambiental, desertificação e entraves ao desenvolvimento sustentável do Ceará. In: PINHEIRO, Daniel R. de C. (Org.). Desenvolvimento sustentável: desafios e discussões. Fortaleza: ABC Editora, 2006. p. 33-55. (ISBN: 85-7536-181-3).

SOUZA, M. J. N.; OLIVEIRA, V. P. V. ; GRANGEIRO, C. M. M.. Análise Geoambiental. In: ELIAS, D. (Org.). O novo espaço da produção globalizada - o baixo Jaguaribe. Fortaleza: FUNCEME, 2002. p. 23 89.

TRICART, J.. Ecodinâmica. Rio de Janeiro: SUPREN, 1977.

\section{AGRADECIMENTOS}

Ao Conselho Nacional de Desenvolvimento Científico e Tecnológico (CNPq) pelo auxílio financeiro à pesquisa e ao Laboratório de Geoprocessamento e Estudos Aplicados (LABGEO).

Recebido em: 14/08/2016

Aceito para publicação em: 01/10/2016 